Goldschmidt 2021 Abstract

https://doi.org/10.7185/gold2021.6426

\section{Linking innovative field measurements to models: characterizingreactive groundwater exchange along large rivers}

MARTIN A BRIGGS ${ }^{1}$, ASHLEY M HELTON ${ }^{2}$, MICHAEL N GOOSEFF $^{3}$, JANET R BARCLAY ${ }^{4}$, NEIL TERRY ${ }^{4}$, ERIC M MOORE $^{2}$, ADAM HAYNES ${ }^{2}$, KEVIN JACKSON ${ }^{2}$, ALAINA BISSON $^{2}$, MARGARET DIGIORNO ${ }^{3}$, EVAN ARNTZEN ${ }^{5}$ AND XINGYUAN CHEN $^{5}$

${ }^{1}$ United States Geological Survey

${ }^{2}$ University of Connecticut

${ }^{3}$ University of Colorado

${ }^{4}$ US Geological Survey

${ }^{5}$ Pacific Northwest National Laboratory

Presenting Author: mbriggs@usgs.gov

Large river corridors integrate a spectrum of localized groundwater exchange processes such as irrigation return flows and legacy contaminant transport, impacting downstream water quality and baseflow supply. Reactive nitrogen $(\mathrm{N})$ applied to land surfaces accumulates in aquifers, creating a source of legacy $\mathrm{N}$ that is later discharged with groundwater along river corridors. Predicting the timing, magnitude, and spatial distribution of legacy $\mathrm{N}$ delivery along large river corridors is complex and necessitates large-scale process-based models paired with comprehensive, local-scale observations. Our field methods integrate emergent remote sensing technologies with radon, water isotope, geochemical, and water flux measurements. In the $8^{\text {th }}$-order Columbia River, Washington USA we deployed extensive multiparameter towed surveys to locate and evaluate zones of subsurface groundwater exchange. Throughout the $5^{\text {th }}$ order Farmington River watershed, Connecticut USA we conducted extensive high-resolution thermal infrared surveys over multiple years to locate, sample, and directly instrument zones of riverbank groundwater discharge. Towed geophysical data were collected along both mainstem rivers to map variations in riverbed geology that can control where groundwater enters the channel. In the Hanford reach of the Columbia River groundwater inflows were found to be more common when discharge fell (dam-controlled) in the late summer. Nitrate concentrations were correlated with inflows from a known groundwater plume and with agricultural land use. In the Farmington River Watershed, we found extensive spatial heterogeneity in groundwater $\mathrm{N}$ concentrations along the main stem, but there were inconsistent relationships to source area land cover. Spatial groundwater discharge patterns were related to large scale bedrock geology and local valley and bank morphology, and temporal flux records generally showed seasonal trends. Through testing various groundwater flow model formulations, we found that simulated groundwater discharge flow path depth, travel time, and network position varied greatly among models. When comparing to thermal infrared data across stream orders, we found that simulated and observed discharge patterns generally agree in large but not small rivers, and that improved modeling approaches are needed in headwaters areas. Together these examples represent the application of a rapidly developing hydrological toolkit for characterizing groundwater exchange along large rivers and informing models in innovative ways.
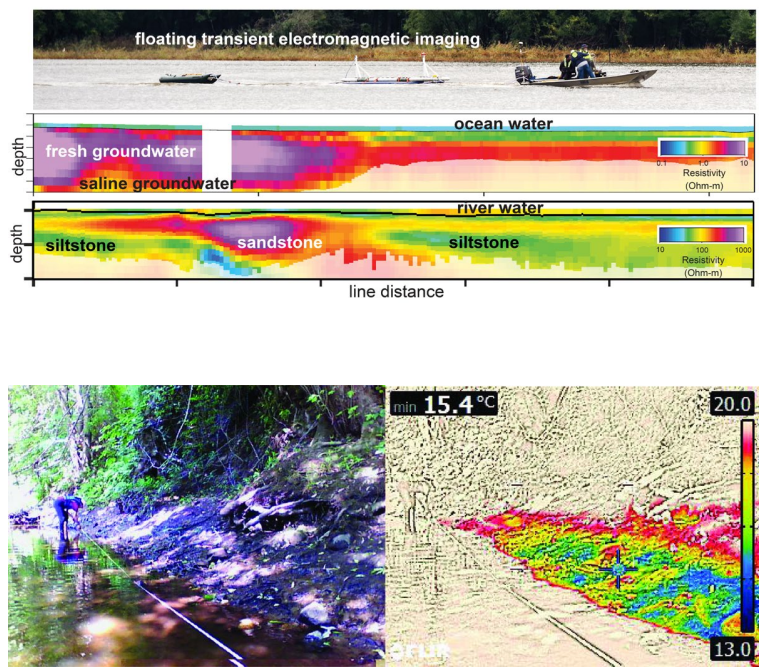